remission in $10-30 \%$ of patients. In the controlled trial performed by Tamminga et al, patients that received clozapine not only had a significant improvement in their TD, when compared to both their own baseline and to those subjects receiving haloperidol, but maintained this improvement for the 12-month duration of the trial. Clozapine doses in all of these studies were similar to those typically used to treat psychosis.

In summary, there exist considerable data, from a wide variety of centres, and including double-blind evidence, all consistent with the hypothesis that clozapine is effective in the treatment of tardive dyskinesia. While clozapine's mechanism of action in TD may remain unclear (Young et al, 1997), its efficacy in this chronic, severe, and often disabling condition appears to be beyond doubt.

CASEY, D. E. (1989) Clozapine: neuroleptic-induced EPS and tardive dyskinesa. Psychopharmacology, 89, S47-S53.

TAMminga, C. A., ThaKer, G. K., MORAN, M., et al (1994) Clozapine in tardive dyskinesla: observations from human and animal model studies. Joumal of Clinical Psychiatry. 65 (suppl B), 102-106.

YOUNG, C. R., LONGHURST, J. G., BOWERS, M. B., et al (1997) The expanding indications for clozapine. Joumal of Clinical and Experimental Psychopharmacology, 6, 1-20.

JAMES G. LONGHURST and ERICA L. WEISS, Department of Psychiatry and Connecticut Mental Health Center, School of Medicine, Yale University. 34 Park Street, New Haven. Connecticut 06519

Sir: Duncan and colleagues have produced an informative review of a complex subject (Psychiatric Bulletin, July 1997, 21, 422-425). The article mentions tardive dystonia only briefly and, understandably, the discussion is weighted towards the management of classic tardive dyskinesia. We wish to comment on the role of botulinum toxin in this area. It is conceded that dystonia occurring as the sole or predominant abnormality of movement among patients with tardive dyskinesia is relatively uncommon. Yassa et al (1992) documented a prevalence ratio for tardive dystonia of $2 \%$ in a prospective study of elderly patients receiving neuroleptic drugs. In comparison orobuccal-lingual stereotypies or stereotypies elsewhere were present in approximately $30 \%$ of the same group. However, in the series of 100 consecutive patients with tardive dyskinesia examined by Stacy et al (1993) stereotypies were observed in $\mathbf{7 8}$ individuals and dystonic movements in 75 . In only 22 of these cases was there dystonia in isolation and clearly in many cases the movements were coexistent. Furthermore both these authors and others have commented that distinction between dystonic movements and stereotypies may at times be very difficult.

Duncan and colleagues state that botulinum toxin is a useful therapy only in cases of tardive dystonia. This statement deserves qualification. First, there may be a dystonic component within a complex dyskinesia amenable to treatment with botulinum toxin. Second, our clinical experience in Middlesbrough and Newcastle would suggest that the stereotypies of classic tardive dyskinesia can also be ameliorated using botulinum toxin (P. D. and M. H.). Tardive dystonia is, however, more frequently a cause of morbidity than stereotypy and our experience of treating dystonia is greater. We would therefore encourage psychiatrists faced with intractable and symptomatic stereotypies, rarer tardive phenomena such as myoclonus and tremor or complex dyskinesias to consider referral to a botulinum toxin clinic even in the absence of a purely dystonic syndrome. Only with such referrals will the true value of botulinum toxin in the treatment of tardive dyskinesias became apparent.

Stacy, M., Cardoso, F. \& Jankovic, J. (1993) Tardive stereotypy and other movement disorders in tardive dyskineslas. Neurology. 43. 937-941.

YASSA. R., NASTASE, C.. DUPONT, D., et al (1992) Tardive dyskinesia in elderly psychiatric patients: a five year study. American Joumal of Psychiatry. 149. 1206-1211.

P. DUFFeY, Lecturer, Department of Clinical Neurosciences, University of Newcastle upon Tyne; J. A. HollaND, Specialist Registrar in Psychiatry, Royal Victoria Infirmary. Newcastle upon Tyne; and M HAWTHORNE, Consultant Otolaryngeal Surgeon, North Riding Infirmary. Newport Road, Middlesborough, Cleveland

\section{Tarasoff and the duty to warn third parties}

Sir: We were interested to read the editorial by Turner \& Kennedy (Psychiatric Bulletin. August 1997, 21, 465-466). They suggest that psychiatric practice in the UK, has altered in recent years towards an increased likelihood of warning third parties, who may be at risk. They relate this to post-Tarasoff discussions and recent UK enquiries (Ritchie et al, 1994).

In 1995 we conducted a postal survey of local Glasgow psychiatrists in which we asked them to indicate their likely response to vignettes which posed issues of confidentiality. We received 53 responses $(59 \%$ of total), 19 respondents were consultants (35.8\%). The first vignette described a 17-year-old out-patient living with her parents and younger sisters who discloses sexual abuse by her father. The patient requests confidentiality. In response 
$24.5 \%$ of all respondents ( $21 \%$ of consultants) would provide information to agencies with a duty to investigate e.g. social work.

The second vignette describes a 38-year-old mildly depressed male out-patient recently separated from his wife. He has no previous history of violence but is described as angry, embittered and aggrieved. He describes often having thoughts (but denies plans) of stabbing his wife and new partner. He specifically states that his wife should not know of his attendance as he fears it may have some bearing on future custody issues. In response $9.4 \%$ of all respondents (5\% of consultants) considered warning the wife and partner or informing the police. All of these respondents suggest that they would first discuss the issue with their defence union or in the case of one consultant disclose information if the risk of enactment was judged to be high.

The results from our survey suggest that psychiatrists in the UK, generally do not 'warn' but are more likely to respect confidentiality. This is in contrast to the authors' contention that psychiatric practice has now altered towards warning third parties. If, as the authors' suggest. there is to be a change in the legal responsibility towards third parties, it may be that the majority of psychiatrists will be changing their practice in response to such, rather than pre-empting such changes.

RTrCHE, J. H., DICK, D. \& LINGHAM, R. (1994) Report of the Inquiry into the Care and Treatment of Christopher Clunis. London: HMSO.

AlleEN Blower, Staff Grade Psychiatrist, Hartfield Clinic, Dumbarton; and MARK COHEN, Senior Registrar in Psychiatry, State Hospital, Carstairs

\section{CPA: faith or fact}

The convergence of traditional cost saving and modern libertarian views, alongside the introduction of effective pharmacotherapy, allowed the 'asylum' closures. Highly desirable 'Care in the Community' was practised with enthusiasm. but without a concrete plan. A very few psychotically-driven violent patients forced the government to introduce the Care Programme Approach (CPA) to reassure society.

The CPA has generated much discussion, but little evidence of efficacy (Marshall, 1996) and even its most vocal supporters have concurred that it may generate an increased workload in the form of admissions and paperwork (Tyrer et al, 1995), while having no impact on suicide rates. Detractors have complained that the CPA is an unproved, unfunded, bureaucratic, unplanned and scape-goating exercise. Evidence also insists that it is not of value in detecting unmet needs or risk' in those who eventually kill themselves.

The general practitioners, who are the key to its success, have little interest in the CPA (Grace et al, 1996).

Much of the argument surrounding the CPA has been semantic in nature. For instance, though the CPA is targeted at the severely mentally ill, the ex-President of the College discouraged the use of this concept (Lacey \& Caldicott, 1996). Others have quibbled over the definitions of case management versus care management.

Some facts should be agreed upon. First, the CPA was introduced without due regard to implementation with the inevitable result of demotivating those needed for its enactment. Second, no extra resources have been allocated. Third, the face validity of CPA efficacy has not been complemented by convincing research evidence and cannot now be effectively studied given its statutory nature. Last, as allocation to the CPA is of necessity a subjective process and resources differ so wildly across the country, no meaningful audit of its use can be performed.

Ultimately the CPA is skewered by its own contradictions and those who beg an alternative must look to their own practice. Legislation cannot substitute for education.

Grace, J., Steels, M. \& Baruah, R. (1996) General practitioners' knowledge of and views on the care programme approach. Psychiatric Bulletin. 20. 643644.

LACEY, H. \& CALDICOTT, F. (1996) Less severe mental illness. Psychiatric Bulletin, 20, 496.

MARSHALL. M. (1996) Case management: a dubious practice. British Medical Journal, 312, 523-524.

TYRER, P., MORGan, J.. VAN HORN, E. et al (1995) A randomised controlled study of close monitoring of vulnerable psychiatric patients. Lancet, 346. 756-759.

ANDREW AL-ADWANI, Specialist Registrar, Doncaster Royal Infirmary; and D. W. NABI, Consultant Psychiatrist for the Elderly. Rotherham General Hospital

\section{Forgetfulness and blame}

I was recently consulted by a solicitor about a client of his who had been accused of, and charged with, theft from an elderly lady for who she, the accused, acted as a home care assistant. She was a middle aged lady of previous lily white reputation. The elderly lady had apparently told her son that money was missing from her pension and it had been stolen by her home care assistant. He reported this to the police and they kept the old person's house under observation. One day the care assistant involved was stopped by the police and was 